\title{
SORPTION OF Ga (III) ON FLEXIBLE OPEN CELL POLYURETHANE FOAM OF POLYETHER TYPE IMPREGNATED WITH TRI-N-BUTHYL PHOSPATE
}

\author{
Lavinia Tofan ${ }^{\mathrm{a}}$, Doina Bilba ${ }^{\mathrm{a}}$, Carmen Paduraru ${ }^{\mathrm{a}}$ and Ovidiu Toma ${ }^{\mathrm{b} *}$ \\ a Department of Environment Engineering and Management, Faculty of Chemical Engineering, “Gh. Asachi” Technical \\ University of Iasi, 71 D.Mangeron Street, 700050 Iasi, Romania \\ ${ }^{\mathrm{b}}$ Department of Biochemistry, Faculty of Biology, "Al.I.Cuza” University of Iasi, 20A Bd. Carol I, 700505 Iasi, Romania \\ *e-mail : otoma@uaic.ro; Tel. (+40 232) 201630 ; Fax (+40 232) 201472
}

\begin{abstract}
The obtained results concerning the Ga (III) ion retention on flexible open cell polyurethane foam of polyether type pretreated with tri-n-butyl phosphate are presented. The influence of solution acidity, phases contact time, Ga (III) concentration and solution temperature have been investigated. The parameters of Ga (III) batch sorption have been optimized. On the basis of Langmuir isotherms, the sorption constants and the thermodynamic parameters, $\Delta \mathrm{G}, \Delta \mathrm{H}$ and $\Delta \mathrm{S}$ have been calculated.
\end{abstract}

Keywords: sorption, polyurethane foam, tri-n-butyl phosphate, gallium.

\section{INTRODUCTION}

The increasing demand for gallium in electronics industry has stimulated research on new materials and methods for the removal, recovery and determination of trace gallium in various natural and industrial samples. In this context, an alternative to the different ion - exchange resins can be represented by polyurethane foams [1]. Polyurethane foams have a wide range of applications in batch or dynamic separation and preconcentration of inorganic and organic species, gas and liquid chromatography and cells imunosorption [2,3].

The main physical and chemical features of polyurethane foams

\begin{tabular}{|l|l|}
\hline \multicolumn{1}{|c|}{ Character } & \multicolumn{1}{|c|}{ Hydrophobic } \\
\hline Porosity & \multicolumn{1}{c|}{ Large } \\
\hline Reversible swelling in & $\begin{array}{l}\text { Water, } \mathrm{HCl} \text { until } 8 \mathrm{M}, \mathrm{H}_{2} \mathrm{SO}_{4} \text { until } 4 \mathrm{M}, \mathrm{HNO}_{3} \text { until } 2 \mathrm{M}, \\
\text { glacial } \mathrm{CH}_{3} \mathrm{COOH}, \mathrm{NH}_{4} \mathrm{OH} 2 \mathrm{M}, \mathrm{NaOH} 2 \mathrm{M} \text {, organic } \\
\text { solvents (benzene, carbon tetrachloride, chloroform, } \\
\text { acetone, alcohols) }\end{array}$ \\
\hline Dissolution in & Concentrated $\mathrm{H}_{2} \mathrm{SO}_{4}$; concentrated $\mathrm{HNO}_{3}$ \\
\hline Degradation by & $\begin{array}{l}\text { Heating to } 180-220^{\circ} \mathrm{C} \\
\text { UV exposure }\end{array}$ \\
\hline Anionic exchange capacity & Low \\
\hline Surface area & High \\
\hline Sorption rate of chemical species & Relative fast \\
\hline
\end{tabular}

The polyurethane foams can be efficiently used both in unloaded form [4-8] and after a physical or chemical treatment [9-15].The remarkable properties (Tab. 1) make flexible open-cell polyurethane foam of polyether type an ideal support for immobilizing by physical adsorption of various selective organic reagents and extractants [16]. Thus, the excellent properties of the flexible open-cell polyether of polyurethane foam type impregnated with the organic extractant tri-n-butyl phosphate (TBP) allowed quantitative separation of silver, gold, bismuth, cadmium, cobalt, chrome, copper, mercury, nickel, lead, palladium, tin, tantalum, thorium [9], and the concentration of iron from chloride media [17] and phenols from waters [18]. 
This paper deals with the experimental results of the retention of gallium ions on polyurethane foam of polyether type pretreated with TBP under specific conditions, giving the sorption isotherms and the values of thermodynamic amounts.

\section{EXPERIMENTAL}

\section{Reagents and Chemicals}

The stock solution of $\mathrm{Ga}(\mathrm{III})(1.584 \mathrm{mg} / \mathrm{mL})$ was prepared by disolving $\mathrm{GaCl}_{3}$ and was gravimetrically standardized ( by precipitation with ammonia). Working solutions were freshly prepared by appropriate dilutions of the stock solution.

The "SPUMATIM" flexible open-cell polyurethane foam of polyether type was purified according to the procedure described in Fig. 1.

\begin{tabular}{l}
\hline \begin{tabular}{c|}
\hline PRETREATMENT for several hours with $\mathrm{HCl}$ solution of $1 \mathrm{~mol} / \mathrm{L}$ \\
\hline RINSING with bidistilled water ( until the washings are free from $\mathrm{Cl}^{-}$ions ) \\
$\qquad$ \\
\hline WASHING with acetone ( for entire removal of organic impurities ) \\
\hline$\downarrow$ \\
\hline DRYING at $70-80^{\circ} \mathrm{C}$ \\
\hline
\end{tabular}
\end{tabular}

Fig.1. Scheme of polyurethane foam purification.

For foam impregnation, tri -n- butyl phosphate (Fluka, Buch, Switzerland) was used. An aqueous solution $(0.5 \%)$ of rhodamine B was used for the spectrophotometric determination of gallium (III). All reagents were of analytical grade. Absorbance measurements were made on a S104D-WPA Linton Cambrige spectrophotometer.

Foam impregnation

In order to impregnation with TBP, the purified foam (cut into cubes of about $5 \mathrm{~mm}$ edge) was equilibrated with the extractant agent. To ensure complete saturation, the cubes of foam were remained overnight in contact with TBP. Then, to remove the excess of TBP, the impregnated foam was washed several times with $4 \mathrm{~mol} / \mathrm{L} \mathrm{HCl} \mathrm{saturated} \mathrm{with}$ TBP. Finally, the TBP- polyurethane foam sorbent was dried and kept in a dessicator. The amount of TBP retained by the foam was of $5.1714 \mathrm{TBP} / \mathrm{g}$ foam. This amount corresponds to an $83.8 \%$ content of TBP in the loaded foam.

\section{General Sorption Procedure for Gallium}

In the sorption systems under study batch conditions have been carried out. The weighed samples of about $0.1 \mathrm{~g}$ of TBP- impregnated foam were equilibrated with volumes of $25 \mathrm{~mL}$ solution containing known and variable amounts of $\mathrm{Ga}$ (III) and $\mathrm{HCl}$. After a determined time of contact, at constant temperature, the phases were separated. The Ga (III) content in supernatant was determined spectrophotometrically, with rhodamine B [19].

\section{RESULTS AND DISCUSSION}

Because of their various functional groups or heteroatoms, unloaded polyurethane foam sorbents which are not chemically inert, take part in the processes of sorption by virtue of their own structure. Thus, the retention of Ga (III) as $\mathrm{HGaCl}_{4}$ on untreated polyether-type polyurethane foams was explained by a polyether extraction mechanism [20,21]. On the other hand, in the mechanism of the sorption by reagent- loaded polyurethane sorbents description, the nature of the physically or chemically imobilized reagent in the foam structure plays a leading role [2,9].

The selection of TBP as modifier agent for the cellular material has been determined by its double function: plasticizer which significantly increases the foam permeability and extractant with high solvation power in ionic association systems.

In order to establish the optimum conditions for $\mathrm{Ga}(\mathrm{III})$ sorption on flexible open cell polyurethane foam of polyether type loaded with tri-n-butyl-phosphate, the effect of solution acidity, phase contact time, Ga(III) concentration and solution temperature have been studied. 
The effect of solution acidity on polyurethane foam-TBP-Ga (III) sorption systems is described by the means of $\mathrm{Ga}$ (III) distribution coefficients. The distribution coefficients $\left(\mathrm{K}_{\mathrm{d}}\right)$ were calculated as ratio between moles of Ga(III) taken up per gram of TBP- loaded foam and moles of $\mathrm{Ga}$ (III) left in $1 \mathrm{~mL}$ solution at equilibrium.

Because the polyurethane foam is partially chemically destroyed in solutions with concentrations of $\mathrm{HCl}$ over $8 \mathrm{~mol} / \mathrm{L}$, the correlation is possible only in the range of $\mathrm{HCl}$ concentration $0-8 \mathrm{~mol} / \mathrm{L}$ [17].

It may be considered that in solutions with concentrations of $1-2 \mathrm{~mol} / \mathrm{L}$ in $\mathrm{HCl}$, the following equation describes rightly the $\mathrm{Ga}$ (III) retention equilibrium on TBP-loaded foam:

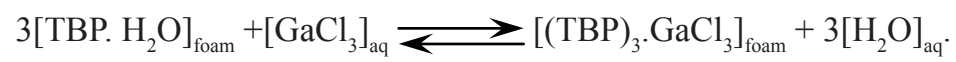

The solution acidity increase $(4-6 \mathrm{~mol} / \mathrm{L}$ in $\mathrm{HCl}$ ) causes a mechanism of oxonium type for Ga (III) sorption (as $\left[\mathrm{GaCl}_{4}\right]^{-}$chlorocomplex):

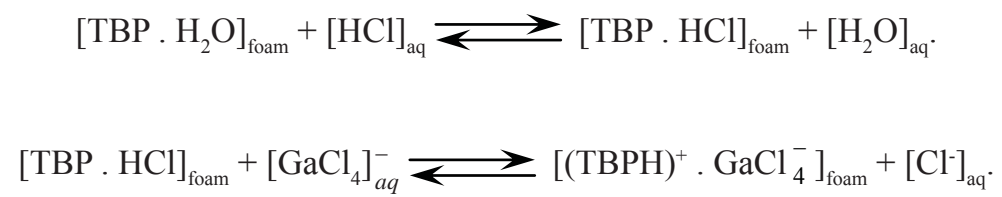

The dependence of Ga (III) distribution coefficients on hydrochloric acid concentrations until $8 \mathrm{~mol} / \mathrm{L}$ is shown in Fig. 2.

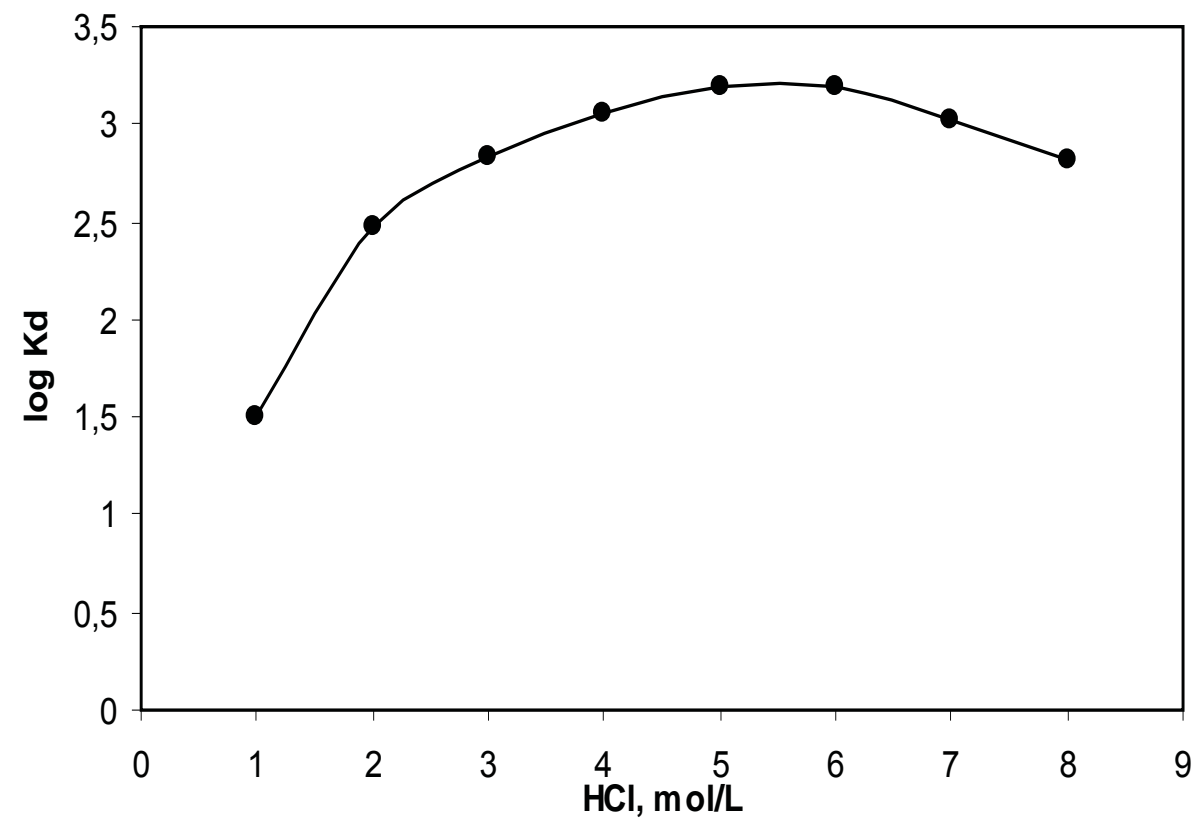

Fig. 2. The effect of $\mathrm{HCl}$ concentration ( $\mathrm{mol} / \mathrm{L})$ on $\mathrm{Ga}(\mathrm{III})$ retention by polyurethane foam impregnated with $\mathrm{TBP}\left(\mathrm{C}_{0}=0.1584 \mathrm{mg} \mathrm{Ga}(\mathrm{III}) / \mathrm{mL}\right.$; shaking time $\left.=1 \mathrm{~h}\right)$.

The competitive effect of $\mathrm{HCl}$ extraction, predominantly to increase of medium acidity, determines a decrease in $\mathrm{Ga}$ (III) retention for $\mathrm{HCl}$ concentrations over $6 \mathrm{~mol} / \mathrm{L}$. This behavior is in good agreement with the proposed mechanism for extraction of $\mathrm{Fe}$ (III) from solutions $4 \mathrm{~mol} / \mathrm{L}$ in $\mathrm{HCl}$ on polyurethane foam pretreated with TBP [17].

The experiments carried out in solutions $6 \mathrm{~mol} / \mathrm{L}$ in $\mathrm{HCl}$ with an initial concentration of $0.1584 \mathrm{mg} \mathrm{Ga}$ (III)/mL revealed an increase of the Ga (III) retention degree with phase contact time increasing (Fig.3). 


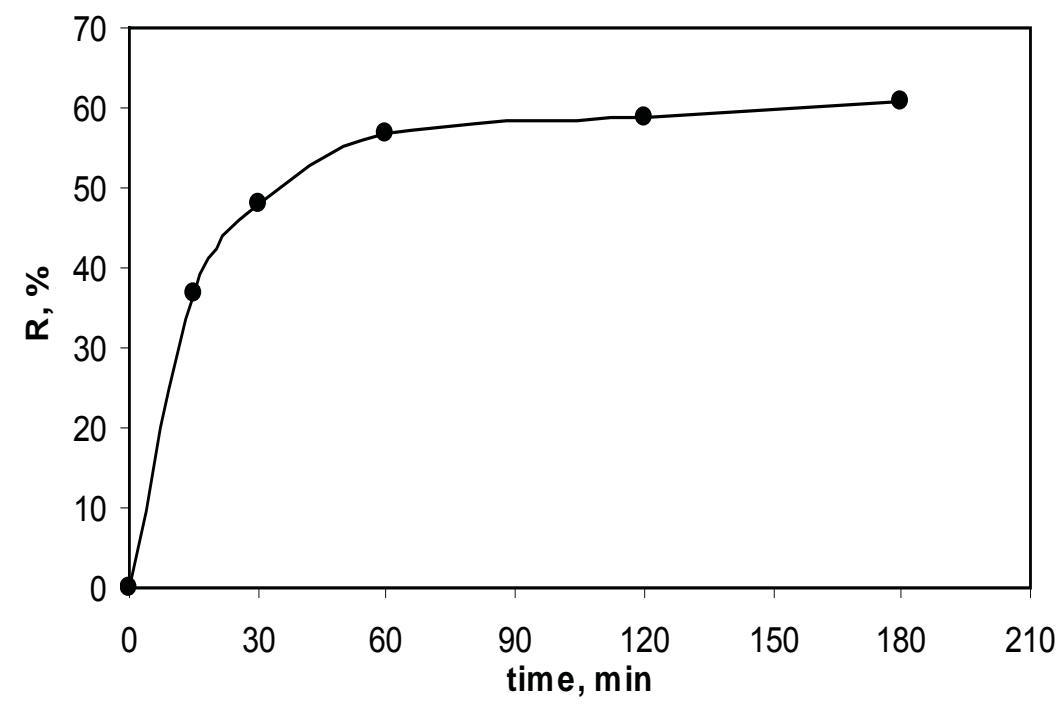

Fig. 3. The effect of phase contact time on Ga (III) retention by TBP-loaded polyurethane foam $\left(\mathrm{C}_{0}=0.1584 \mathrm{mg} \mathrm{Ga}(\mathrm{III}) / \mathrm{mL}\right)$.

The equilibrium of Ga (III) sorption on polyurethane foam impregnated with TBP is reached after about $2 \mathrm{~h}$ from phase contact.

Fig. 4.

The influence of the initial concentration $\left(\mathrm{C}_{0}\right)$ on Ga (III) sorption by TBP - polyurethane foam is giving in

The amount of $\mathrm{Ga}$ (III) sorbed from solutions $6 \mathrm{~mol} / \mathrm{L}$ in $\mathrm{HCl}$, at two different temperatures, increases with increasing initial concentrations. This trend can be explained by assuming that surface sorption sites play a leading role in the systems under study. Higher initial concentrations might be closely associated with high values of the ratio between the initial number of $\mathrm{Ga}$ (III) mmoles and the finite number of surface active sites, thus resulting in an enhancement of the metal uptake.

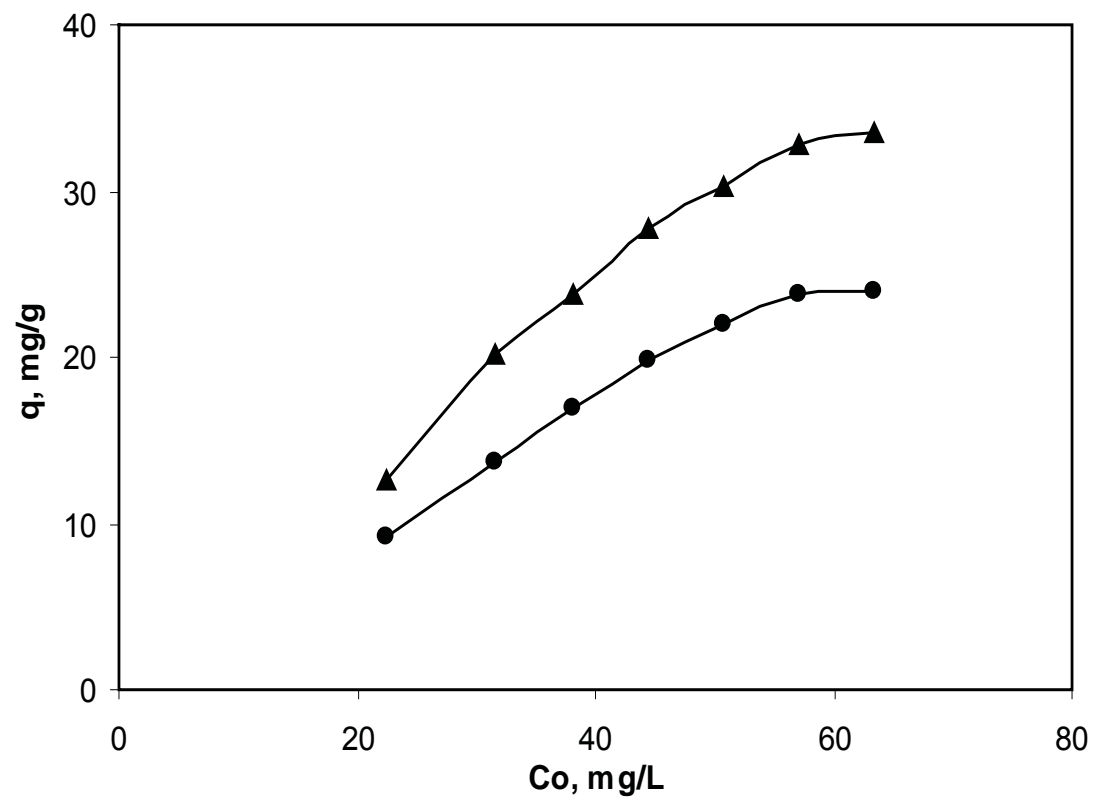

Fig. 4. The influence of initial concentration on Ga (III) - TBP - polyurethane foam sorption systems, at different temperatures $(\bullet)-278 \mathrm{~K} ;(\boldsymbol{\Delta})-313 \mathrm{~K}$. 


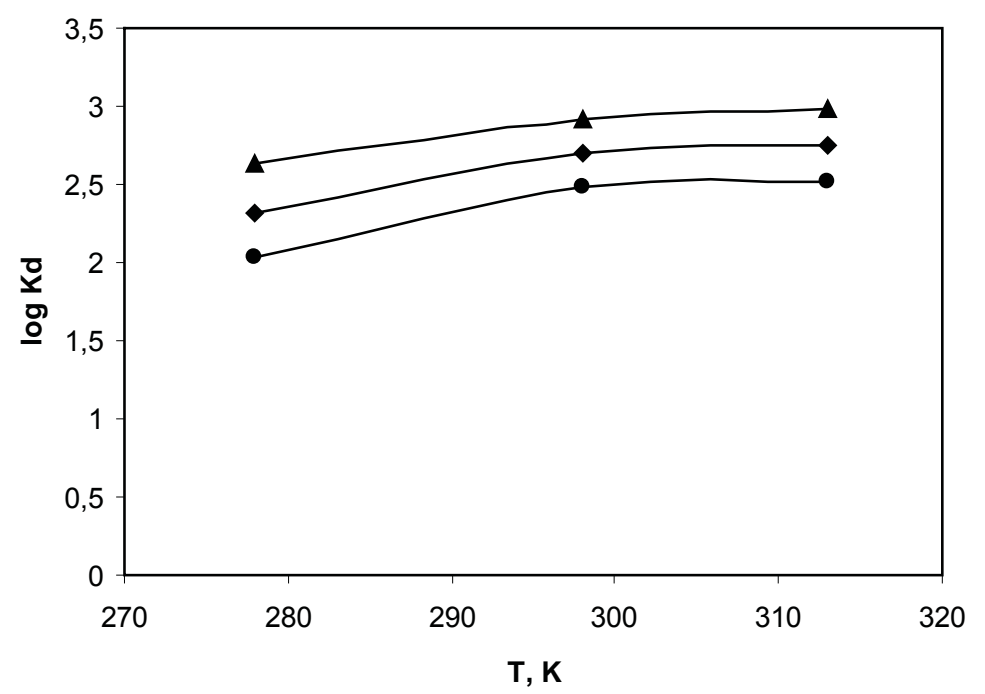

Fig.5. The effect of the temperature on Ga (III) retention by TBP - impregnated polyurethane foam, $(\bullet)-\mathrm{C}_{0}=19 \mathrm{mg} / \mathrm{L} ;(\bullet)-\mathrm{C}_{0}=31.7 \mathrm{mg} / \mathrm{L} ;(\boldsymbol{\Delta})-\mathrm{C}_{0}=44.3 \mathrm{mg} / \mathrm{L}$.

The amount of $\mathrm{Ga}$ (III) sorbed from solutions $6 \mathrm{~mol} / \mathrm{L}$ in $\mathrm{HCl}$, at two different temperatures, increases with increasing initial concentrations. This trend can be explained by assuming that surface sorption sites play a leading role in the systems under study. Higher initial concentrations might be closely associated with high values of the ratio between the initial number of Ga (III) mmoles and the finite number of surface active sites, thus resulting in an enhancement of the metal uptake.

Fig. 5 presents the influence of temperature on Ga (III) retention by TBP - loaded polyurethane foam from solutions of different initial concentrations.

The $\lg \mathrm{K}_{\mathrm{d}}=\mathrm{f}(\mathrm{T})$ curves in Fig. 5 have the same shape in all solutions. The high values of distribution coefficients $\left(\mathrm{K}_{\mathrm{d}}\right)$ indicate a good affinity of the TBP-polyurethane foam toward Ga (III); with increasing temperature the retention of $\mathrm{Ga}$ (III) is higher, suggesting an endothermic chemical process.

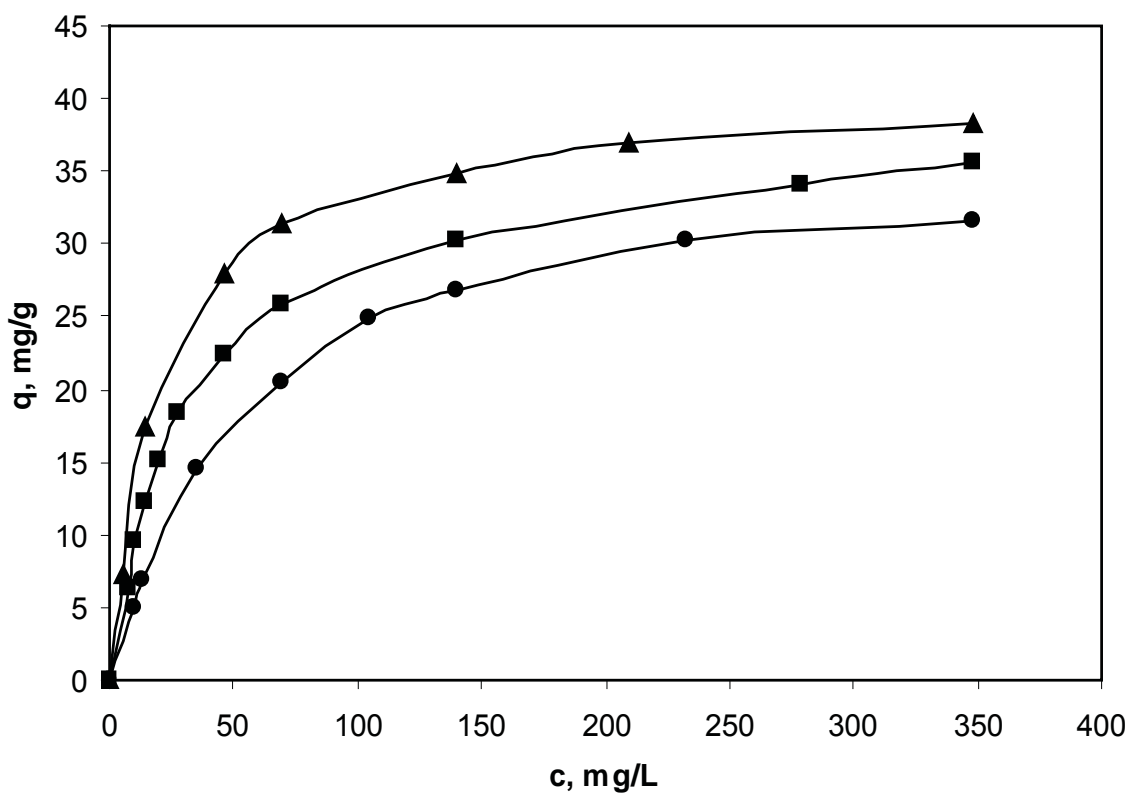

Fig. 6. Ga (III) isotherms of sorption on TBP loaded polyurethane foam, at different temperatures $(\bullet)-278 \mathrm{~K} ;(\boldsymbol{\bullet})-295 \mathrm{~K} ;(\boldsymbol{\Delta})-313 \mathrm{~K}$. 
Plotting the variation of the retained amount of Ga (III) on solid phase ( $\mathrm{mg} / \mathrm{g}$ ) versus the Ga(III) concentration left in solution at equilibrium $(\mathrm{mg} / \mathrm{L})$, at constant temperatures, the sorption isotherms represented in Fig. 6 are obtained.

The shape of isotherms in Fig.6 allowed a quantitative characterization of Ga (III) sorption. In this context, we used the equation of Langmuir type in linear form:

$$
\mathrm{c} / \mathrm{q}=\mathrm{c} / \mathrm{q}_{0}+1 / \mathrm{K}_{\mathrm{L}} \cdot \mathrm{q}_{0}
$$

where: $\mathrm{q}$ is the amount of sorbed Ga (III) on solid phase ( $\mathrm{mg} / \mathrm{g}$ foam); $\mathrm{c}$ is the Ga(III) concentration in solution at equilibrium (mg/L); $\mathrm{q}_{0}$ is the saturation sorption capacity ( $\mathrm{mmol} / \mathrm{g}$ foam); $\mathrm{K}_{\mathrm{L}}$ is a parameter related to the strength of the sorbed ion- sorbent binding $(\mathrm{L} / \mathrm{mol})$.

The sorption isotherm constants $\left(\mathrm{q}_{0}\right.$ and $\left.\mathrm{K}_{\mathrm{L}}\right)$ calculated from intercepts and slopes of corresponding linear Langmuir plots for Ga (III) sorption by untreated polyurethane foam and TBP- polyurethane foam at different temperatures, together with their correlation coefficients $\left(\mathrm{R}^{2}\right)$ are given in Table 2.

Table 2

\section{Langmuir constants}

\begin{tabular}{|c|c|c|c|}
\hline $\mathrm{T}, \mathrm{K}$ & $\mathrm{R}^{2}$ & $\mathrm{q}_{0}, \mathrm{mmol} / \mathrm{g}$ & $\mathrm{K}_{\mathrm{L}}, \mathrm{L} / \mathrm{mol}$ \\
\hline \multicolumn{5}{|c|}{ Polyurethane foam impregnated with TBP } \\
\hline 278 & 0.9994 & 0.5301 & 1262.87 \\
\hline 295 & 0.9993 & 0.5535 & 2216.2 \\
\hline 313 & 0.9999 & 0.5835 & 3424 \\
\hline \multicolumn{3}{|c|}{ Untreated polyurethane foam } \\
\hline 295 & 0.9952 & 0.4873 & 1526.7 \\
\hline
\end{tabular}

Although Ga (III) is well retained on untreated foam, Tab. 2 points out that the analytical performances of the cellular material in sorption of Ga (III) traces were significantly improved by its impregnation with tri-n-butyl phosphate. Therefore the combination between the advantages of liquid extraction and chromatography techniques in TBP-loaded foam case result in sorption systems with high practical applicability.

As can be seen from Table II, on temperature increase, the saturation sorption capacity increases. This finding is in good agreement with viscosity water decrease on rising temperature, so that the penetrability of water and sorbed species in polyurethane sorbent pores is increased.

For a thermodynamic description in polyurethane foam-TBP-Ga (III)- $\mathrm{HCl}$ sorption systems the $\Delta \mathrm{G}, \Delta \mathrm{H}$ and $\Delta \mathrm{S}$ values were calculated (Tab. 3) by means of the following usual relations:

$$
\begin{aligned}
& \Delta \mathrm{G}=-\mathrm{RT} \ln \mathrm{K}_{\mathrm{L}} \\
& \ln \mathrm{K}_{\mathrm{L}}=\text { constant }-\Delta \mathrm{H} / \mathrm{RT} \\
& \Delta \mathrm{S}=(\Delta \mathrm{H}-\Delta \mathrm{G}) / \mathrm{RT}
\end{aligned}
$$

where $\mathrm{R}$ is gas constant and $\mathrm{T}$ is the absolute temperature .

The thermodynamic parameters characteristic to Ga (III) sorption on polyurethane foam

\begin{tabular}{|c|c|c|c|}
\hline $\mathrm{T}, \mathrm{K}$ & $\Delta \mathrm{G}, \mathrm{kJ} / \mathrm{mol}$ & $\Delta \mathrm{H}, \mathrm{kJ} / \mathrm{mol}$ & $\Delta \mathrm{S}, \mathrm{J} / \mathrm{mol} . \mathrm{K}$ \\
\hline \multicolumn{4}{|c|}{ Polyurethane foam impregnated with TBP } \\
\hline 278 & -16.496 & 20.317 & 132.42 \\
\hline 295 & -18.883 & & 132.88 \\
\hline 313 & -21.967 & - & 132.53 \\
\hline \multicolumn{5}{|c|}{ Untreated polyurethane foam } \\
\hline 295 & -17.96 & - \\
\hline
\end{tabular}

The negative values of free energy changes $(\Delta G)$ for all temperatures show a reasonable affinity of polyurethane foam against $\mathrm{Ga}$ (III) ions (spontaneous process of sorption). The positive value of $\Delta \mathrm{H}$ (variation of enthalpy accompanying the $\mathrm{Ga}(\mathrm{III})$ sorption indicates an endothermic process, facilitated by higher temperatures. The positive entropy changes 
$(\Delta \mathrm{S})$ characterize an increase in the disorder of the system on $\mathrm{Ga}$ (III) sorption by the polyurethane foam (probably due to the release of hydration water molecules surrounding the gallium ions).

We experimentally found that temperature rising contributes to a faster attainment of equilibrium, namely an increase of the sorption rate explained by an increase in Ga (III) diffusion rate from chlorhydric solutions to impregnated foam.

\section{CONCLUSIONS}

The affinity of flexible open cell polyurethane foam of polyether type for Ga (III) is improved by its impregnation with the organic extractant tri-n-butyl phosphate. If for untreated foam, Ga (III) retention may be explained by a polyether extraction mechanism, in the case of impregnated foam, the advantages of liquid-liquid extraction and chromatography techniques are combined.

The $\mathrm{Ga}$ (III) retention from solutions $6 \mathrm{~mol} / \mathrm{L}$ in $\mathrm{HCl}$ on polyurethane foam pretreated with TBP is favored by the increase of phase contact time, the concentration of gallium in external solutions and the temperature.

\section{REFERENCES}

[1] Carvalho, M.S.; Neto, K.C.M.; Nobrega A.W.; Medeiros J.A., Se. Sci. and Technol. , 2000, $35(1), 57$.

[2] Braun T.;Navrati, J.D.; Farag, A.B., Polyurethane Foam Sorbents in Separation Science, CRC Press, Inc., Boca Raton, Florida, 1985.

[3] Dmitrienko, S.G.; Zolotov, Y.A., Russ. Chem. Rev. C/C of Uspekhi, 2002, 71(2), 159.

[4] Tofan, L.; Bilba, D.; Nacu, A., Mat. Plast. (Bucharest), 1994, 31, 245.

[5] Dmitrienko, S.G.; Pyatkova, L.N.; Zolotov, Y.A., J. Anal. Chem. , 2002, 57(10), 875.

[6] Abbas, M.N.; El-Assy, N.B.; Abdel Moniem, S., Anal. Lett. , 1989,22, 1555.

[7] Dmitrienko, S.G.; Shapovalova, E.N.; Kochetova, M.V.; Shpigun, O.A.; Zolotov, Y.A., J. Anal. Chem., 2002, 57(11), 1009.

[8] Dmitrienko, S.G.; Goncharova, L.V.; Runov, V.K.; Zakharov, V.N.; Aslanov, L.A., Russ. J. Phys. Chem., 1997, 71(12), 2014.

[9] Palagyi, S.; Braun,T., Elements and Inorganic Species on Solid Polyurethane Foam Sorbents in Preconcentration Techniques for Trace Elements, CRC Press, Boca Raton Ann Arbor London, 1993, pp 364.

[10] Tofan, L., Bilba, D. ; Nacu, A. ; Paduraru, C., Mat. Plast. (Bucharest), 1995, 32, 210.

[11] Elhossein, A.M.; Zaid, M.A.; El-Shahat, M.F., International Journal of Environmental and Analytical Chemistry, 2004, 12(15), 935.

[12] Saeed, M.M.; Ahmad, R., Radiochim. Acta, 2005, 93(6), 333.

[13] Matos, G.D.; Tarley, C.R.T.; Ferreira, S.L.C.; Arruda, M.A.Z., Ecletica Quimico , 2005, 30(1), 65.

[14] Moawed, E.A.; Zaid, M.A.A.; El-Shahat, M.F., Acta Chromatographica, 2005, 15, 220.

[15] Moawed, E.A., Acta Chromatographica, , 2004, 14, 198.

[16] Tofan, L.; Paduraru, C.; Bilba, D. ; Nacu, A., Bull.Polyt. Inst. (Jassy), 1996, 36, 31.

[17] Bilba, D.; Tofan, L.; Paduraru, C. ; Nacu, A., Rev. Roum. Chim., 1998, 43, 493.

[18] El-Shahaw, M.S.; Farag, A.B.; Mostafa, M.R., Sep. Sci. Technol. , 1994, 29(2), 289.

[19] Sandel, E.B., Colorimetric Determination of Traces of Metals, Interscience, New York, 1959, pp 475.

[20] Gesser, H.G.; Bock, E.; Baldwin, W.G.; Chow, A.; McBrideand, D.W.; Lipinski, W., Sep. Sci. Technol., 1976, 11,317 .

[21] Gesser, H.D.; Horsfall, G.A., J. Chim. Phys., 1977, 74, 1072. 